\title{
Peran Resiliensi dan Iklim Organisasi terhadap Work Engagement
}

\author{
Nurlintang Fitri Listya Astika ${ }^{1}$, Ridwan Saptoto ${ }^{2}$ \\ ${ }^{1,2}$ Fakultas Psikologi Universitas Gadjah Mada
}

\begin{abstract}
The uncertain state of the mining industry has impacts to the declining of the demand for the heavy equipment industry sector. One of the effort to keep the company survive to face the challenge is improving the quality of production. This essential effort can be achieved by enhancing work engagement. This study aims to determine the role of resilience and organizational climate on work engagement. The hypothesis of this study was: resilience and organizational climat simultaneously predict the work engagement. The subjects for this research were 63 employees in PT. Komatsu Indonesia. The instrument in collecting the data was a questionnaire. The result of the multiple regression shows that this study's hypothesis is rejected. Resilience and organizational climate cannot simultaneously predict the work engagement. Resilience can significantly predict work engagement by $p=0.004(p<0.05)$, but organizational climate cannot significantly predict it as seen in $p=0.235(p>0.05)$.
\end{abstract}

Keywords : organizational climate, resilience, work engagement

Abstrak. Keadaan industri pertambangan yang sedang tidak menentu berdampak pada turunnya permintaan pada sektor industri alat berat. Salah satu usaha agar perusahaan tetap bisa bertahan menghadapi tantangan tersebut adalah dengan meningkatkan kualitas barang produksi, cara untuk mencapai tujuan tersebut dapat dilakukan dengan meningkatkan work engagement. Penelitian ini bertujuan untuk mengetahui peran resiliensi dan iklim organisasi terhadap work engagement. Hipotesis yang diajukan dalam penelitian ini adalah resiliensi dan iklim organisasi secara bersama-sama dapat berperan dalam meningkatkan work engagement. Subjek dalam penelitian ini adalah karyawan PT. Komatsu Indonesia yang berjumlah 63 orang. Hasil analisis regresi menunjukan bahwa hipotesis dalam penelitian ini ditolak. Variabel resiliensi dan iklim organisasi tidak dapat secara bersama-sama berperan dalam meningkatkan work engagement. Resiliensi dapat memprediksikan work engagement secara signifikan dengan nilai p sebesar 0,002 $(\mathrm{p}<0,05)$ sedangkan iklim organisasi tidak dapat memprediksikan work engagement secara signifikan dengan nilai $\mathrm{p}$ sebesar $0,340(\mathrm{p}>0,05)$.

Kata kunci: iklim organisasi, resiliensi, work engagement

${ }^{1}$ Korespondensi mengenai isi artikel ini dapat dilakukan melalui: ${ }^{1}$ nurlintang.fitri.l@mail.ugm.ac.id

2 Atau melalui ridwan_psychology@ugm.ac.id 
Persaingan menjadi salah satu ciri khas tersendiri di era globalisasi. Naik turunnya kondisi perekonomian menjadi fenomena yang tidak dapat dihindari. Badan Pusat Statistik (2015) melaporkan bahwa keadaan ekonomi Indonesia sedang mengalami adanya perlambatan. Data di lapangan menunjukkan bahwa bidang usaha yang mengalami penurunan drastis adalah pertambangan. Kondisi itu berdampak pada industri terkait, salah satunya adalah industri alat berat. Terjadi penurunan permintaan yang diikuti dengan penurunan pendapatan khususnya pada penjualan produk yang berkaitan dengan pertambangan. Perubahan tersebut memberikan tuntutan pada organisasi untuk mampu beradaptasi, mempunyai ketahanan, mampu melakukan perubahan arah dengan cepat, dan lebih berorientasi pada pelanggan (Waluyo, 2013). Selain itu, perusahaan juga harus dapat melakukan improvement agar dapat bersaing dengan perusahaan alat berat lain. Perusahaan yang tidak mampu melakukan persaingan maka akan semakin terancam keberadaannya. Kualitas produk menjadi sesuatu yang harus diperhatikan bagi organisasi untuk bertahan dalam menghadapi persaingan tersebut. Oleh karena itu, banyak perusahaan yang berlomba-lomba meningkatkan kualitas produknya agar bisa diterima oleh para konsumen.

PT. Komatsu Indonesia merupakan salah satu perusahaan alat berat terkemuka di Indonesia dan menjadi pelopor di Asia Tenggara. Perusahaan ini termasuk industri berskala internasional dengan produk yang inovatif dan berkualitas tinggi. PT. Komatsu Indonesia tidak hanya memproduksi unit jadi seperti buldoser, dumpt truck dan eksavator hidrolik tetapi juga frame, hasil pengecoran baja serta komponen terkait yang akan dipasok ke komatsu seluruh dunia (Komatsu, 2012). PT. Komatsu Indonesia terus berusaha meningkatkan kepuasan pelanggan dengan menerapakan kebijakan TQM (Total Quality Management). Kebijakan tersebut bertujuan untuk mengintegrasikan seluruh fungsi organisasi agar terfokus pada kebutuhan pelanggan dan tujuan organisasi. Salah satu kunci penting dalam implementasi TQM adalah karyawan yang engaged. Tantangan di dunia industri selanjutnya tidak hanya mempertahankan karyawan yang berbakat saja tetapi bagaimana menjadikan karyawan tersebut engaged (Sathiskumar \& Karthikeyan, 2014). Oleh karena itu, dibutuhkan karyawan PT. Komatsu Indonesia yang memiliki work engagement tinggi agar tujuan organisasi dapat tercapai.

Work engagement merupakan salah satu faktor penting dalam organisasi bisnis untuk menghadapi persaingan pasar yang ketat karena akan berhubungan dengan performa baik individu ataupun perusahaan (Bakker \& Leiter, 2010). Menurut Kahn (1990) work engagement didefiniskan sebagai bentuk optimalisasi keterikatan anggota organisasi terhadap peran kerja mereka dengan melibatkan aspek fisik, kognitif maupun emosional. Menurut Schaufeli dan Bakker (2003) work engagement didefinisikan sebagai kondisi pikiran yang positif, penuh, dan terhubung dengan pekerjaan yang ditandai dengan vigour, dedication dan absorption. Vigour dicirikan dengan tingginya tingkat energi dan ketahanan mental saat bekerja, kemauan untuk menginvestasikan usaha pada pekerjaan, dan kegigihan saat menghadapi kesulitan. Dedication mengacu pada keterlibatan kuat individu terhadap pekerjaannya, dan mengalami perasaan 
signifikan, antusiasme, inspirasi, kebanggaan, serta tantangan. Absorption, ditandai dengan konsentrasi sepenuhnya dan rasa senang pada pekerjaan, sehingga waktu terasa cepat berlalu ketika bekerja dan individu kesulitan untuk melepaskan diri dari pekerjaan.

Schaufeli dan Bakker (2003) mengemukakan bahwa work engagement dapat dipengaruhi oleh personal resource dan job resource. Personal resource merupakan evaluasi diri positif terkait dengan ketahanan yang merujuk kepada kemampuan individu untuk melakukan kontrol dan nantinya akan berpengaruh terhadap lingkungannya (Hobfoll, Johnson, Ennis \& Jackson dalam Xanthopoulou, Bakker, Demerouti, \& Schaufeli, 2007). Menurut Sweetman dan Luthans (2010) personal resource meliputi self efficacy, optimis, harapan dan resiliensi. Individu akan menggunakan personal resources, salah satunya resiliensi untuk dapat menjadikan dirinya engaged terhadap pekerjaannya. Resiliensi akan menjadi faktor penghambat stres individu dalam menghadapi tuntutan pekerjaan. Resiliensi yang rendah akan memicu tingkat stres yang tinggi dan memunculkan disengagement pada individu.

Resiliensi didefinisikan sebagai kemampuan seseorang dalam mengatasi setiap kesulitannya dan segala peristiwa yang tidak menyenangkan. Mereka berhasil dalam melakukan penyesuaian dari sebuah perubahan atau segala sesuatu yang tidak dapat diprediksikan (Mc Eween, 2011). Definisi lain menyebutkan bahwa resiliensi adalah kualitas individu untuk tetap berkembang dalam menghadapi kesulitan. Individu dengan resiliensi tinggi memiliki ciri, yaitu dapat melihat perubahan atau stres sebagai suatu tantangan, komitmen, mengetahui batas kontrol, menerima dukungan dari orang lain, memiliki hubungan yang akrab dan aman dengan individu lain, memiliki tujuan pribadi maupun kelompok, self efficacy, menggunakan stres untuk memperkuat diri, melibatkan kesuksesan masa lalu, kontrol yang realistis, rasa humor, berorientasi pada tindakan, sabar, toleransi terhadap afek negatif, beradaptasi terhadap perubahan, optimis, dan memiliki kepercayaan terhadap Tuhan.

Penelitian yang dilakukan oleh Orthman, Ghazali dan Ahmad (2013) mengungkapkan bahwa resiliensi berhu-bungan positif dengan performa yang baik dalam sebuah organisasi. Selain itu, penelitian lain juga dilakukan oleh Mase dan Tyokya (2014) yang mengemukakan mengenai hubungan positif antara resiliensi dan work engagement. Hasil penelitian tersebut menunjukkan bahwa tingginya resiliensi karyawan akan diikuti dengan tingginya work engagement. Karyawan yang mampu bertahan dan mampu mengatasi segala bentuk kejadian negatif dalam organisasi cenderung memilik work engagement yang tinggi.

Hal tersebut membuktikan bahwa para pekerja yang resilien akan terkoneksi secara psikologis terhadap pekerjaannya. Setiap tantangan dan kesulitan yang mereka hadapi tidak dipandang sebagai suatu penghalang. Hal tersebut akan berkebalikan dengan orang yang memiliki resiliensi rendah, mereka akan cenderung mengalami burnout didalam pekerjaannya (Rushton, Batcheller, Schroader \& Donuhue, 2015).

Faktor lain yang memengaruhi work engagement adalah job resource. Job resource mengacu pada aspek-aspek fisik, psikologis, sosial, atau organisasi dari pekerjaan yang dapat mengurangi kerugian yang terkait 
faktor psikologis, dapat membantu dalam mencapai tujuan kerja serta merangsang adanya pertumbuhan, pembelajaran dan pengembangan pada diri karyawan (Schaufeli dan Bakker, 2004). Menurut Bakker, Demerouti dan Xanthopolou (2007) job resource yang berperan dalam pembentukan work engagement diantaranya adalah kontrol pekerjaan, dukungan atasan, informasi, apresiasi, inovasi dan iklim organisasi. Iklim organisasi menjadi sesuatu yang penting dalam work engagement. Iklim organisasi akan menjadi salah satu penguat individu dalam menghadapi lingkungan kerja yang penuh tekanan. Lingkungan yang baik dapat membuat pekerjaan cepat terselesaikan dan tujuan juga akan tercapai.

Menurut Suarez, Muniz, Alvarez, Pedrero dan Cueto (2013) iklim organisasi adalah persepsi karyawan mengenai konstruk molar dari sekumpulan aspek seperti: organisasi kerja, relasi, kerja sama, penghargaan, jam kerja dan keseimbangan kehidupan kerja, otonomi, inovasi, partisipasi, dan keterikatan terhadap pekerjaan. Iklim organisasi juga dapat didefinisikan sebagai persepsi bersama dan makna dari sebuah kebijakan, praktik maupun prosedur dari pengalaman dan perilaku karyawan yang mereka amati dari perolehan penghargaan, dukungan dan harapan (Scneider, Ehrahart \& Macey, 2013).

Iklim organisasi merupakan bagian dari sumber daya pekerjaan yang dapat menurunkan efek dari job demand dan berpengaruh terhadap work engagement. (Bakker, 2011). Penelitian yang dilakukan oleh Koch (2013) mengungkapkan bahwa iklim organisasi memiliki hubungan positif dengan work engagement. Karyawan yang memiliki hubungan baik dengan rekan kerja dan saling bekerja sama dapat meningkatkan efektivitas ketika menjalankan peran kerjanya. Kolaborasi yang efektif tersebut menjadikan pekerjaan lebih cepat selasai. Akibatnya, karyawan memiliki lebih banyak waktu bersama keluarga dan teman sehingga tingkat stres karyawan rendah. Hal tersebut menjadikan karyawan memiliki pengalaman positif yang dapat mengarahkan pada work engagement.

Berdasarkan paparan di atas, dapat disimpulkan bahwa resiliensi dan iklim organisasi dapat berperan positif dalam meningkatkan work engagement karyawan. Resiliensi karyawan yang tinggi akan menjadikan individu lebih mudah beradaptasi dalam kondisi apapun sehingga akan berhubungan dengan performa dalam bekerja. Iklim organisasi yang tinggi juga akan mamberikan dampak pada karyawan untuk memberikan kinerja terbaik mereka.

\section{Metode}

Subjek dalam penelitian ini adalah karyawan PT. Komatsu Indonesia baik direct maupun indirect. Karyawan direct adalah karyawan yang pekerjaannya berhubungan langsung dengan proses produksi, sedangkan karyawan indirect adalah karyawan yang pekerjaannya tidak berhubungan langsung dengan proses produksi. Jumlah subjek yang terlibat dalam penelitian ini yaitu 63 karyawan PT. Komatsu Indonesia yang berasal dari departemen foundry dan hydrolic. Subjek tersebut merupakan karyawan tetap dari PT. Komatsu Indonesia.

Skala work engagement yang digunakan dalam penelitian ini adalah UWES atau Utrecht Work Engagement Scale yang terdiri dari 17 aitem. Skala tersebut dikembangkan oleh Bakker dan Shaufeli pada tahun 2003. Skala ini terdiri dari 3 aspek, yaitu vigor, dedication dan absorption. Model respon yang 
digunakan terdiri dari 7 pilihan yaitu tidak pernah dengan skor 1 , hampir tidak pernah (beberapa kali dalam setahun) skor 2, jarang (satu bulan sekali) skor 3, kadang-kadang (beberapa kali dalam satu bulan) skor 4, sering (sekali dalam satu minggu) skor 5, sangat sering (beberapa kali dalam satu minggu) skor 6, selalu (setiap hari) skor 7 . Semakin tinggi skor yang diperoleh menunjukkan semakin tinggi tingkat work engagement karyawan.

Resiliensi diukur dengan menggunakan CD-RISC atau Connor Davidson Resilience Scale tahun 2003. Skala ini mengukur resiliensi berdasarkan aspek yang dikembangkan oleh Connor dan Davidson yaitu (1) Kompetensi pribadi, standar yang tinggi dan kegigihan (2) Kepercayaan terhadap intuisi, toleransi terhadap afek negatif dan stres, (3) Penerimaan positif terhadap perubahan dan hubungan yang akrab (4) Kontrol diri dan kemampuan mendapatkan bantuan dari orang lain serta (5) Pengaruh spiritual. Semakin tinggi skor yang diperoleh menunjukkan semakin tingginya resiliensi. Skala ini terdiri dari 25 aitem dengan penggunaan respon berbentuk likert yang terdiri dari lima pilihan yaitu Sangat Tidak Sesuai (1), Tidak Sesuai (2), Netral (3), Sesuai (4), Sangat Sesuai (5).

Selanjutnya, variabel iklim organisasi diukur dengan menggunakan Climate Organizational Scale (CLIOR) yang dikembangkan oleh Suarez, Muniz, Alvarez, Pedrero dan Cueto tahun 2013. Aspek iklim organisasi yang digunakan dalam penelitian ini yaitu otonomi, kerjasama, penghargaan, keseimbangan kehidupan kerja, work organization, partisipasi, relasi, inovasi dan kelekatan terhadap pekerjaan. Aitem dalam skala ini berjumlah 50 aitem yang terdiri dari aitem favorable dan unfavorable. Skor yang tinggi dalam skala ini menunjukan bahwa iklim organisasi di dalam perusahaan tersebut tinggi sedangkan skor rendah akan menunjukkan hal yang sebaliknya.

Metode analisis yang digunakan dalam penelitian ini adalah analisis regresi. Analisis regresi akan menentukan arah maupun kekuatan hubungan antara beberapa variabel independen dengan variabel dependen (Kleinbaum \& Kupper, 1978). Analisis ini akan dilakukan dengan bantuan software IBM SPSS 23.

\section{Hasil}

Berdasarkan hasil analisis regresi tersebut menunjukkan bahwa variabel resiliensi signifikan berperan dalam meningkatkan work engagement dengan nilai signifikansi $0,004(p<0,05)$. Nilai koefesien determinasi dari hubungan variabel resiliensi dan iklim organisasi adalah 0,129 . Nilai tersebut berarti bahwa peranan resiliensi dalam memprediksikan work engagement adalah 12,9\% dan sisanya dipengaruhi oleh variabel lain yang tidak dibahas dalam penelitian ini. Variabel iklim organisasi dalam penelitian ini tidak signifikan dalam memprediksikan work engagement. Nilai signifikansi variabel iklim organisasi tidak memenuhi standar batas pengukuran signifikansi yaitu 0,235 ( $\mathrm{p}>0,05)$. Oleh karena itu dapat disimpulkan bahwa hipotesis dalam penelitian ini ditolak karena dari dua prediktor yang diajukan hanya satu prediktor saja yang signifikan berperan dalam work engagement. Hasil analisis variabel resiliensi dengan work engagement menghasilkan persamaan regresi sebagai berikut :

$$
\mathbf{Y}=\mathbf{B}+\mathbf{B}_{1 \times 1} \mathbf{1}
$$

Work engagement $=58,734+0,373$ Resiliensi 
Nilai konstanta 58,734 menjelaskan bahwa, jika nilai variabel resiliensi sama dengan nol maka rata-rata tingkat work engagement karyawan sebesar 58,734. Bila koefesien resiliensi meningkat satu maka work engagement karyawan akan meningkat 0,373 . Koefesien yang bernilai positif menunjukkan hubungan yang positif dari setiap variabel.

\section{Diskusi}

Work engagement merupakan salah satu pendekatan strategis untuk melakukan improvement dalam sebuah perusahaan. Work engagement dapat dikatakan sebagai perasaan emosi positif terkait dengan pekerjaan, perasaan mampu melakukan manajemen diri dalam situasi beban kerja yang tinggi, memiliki pandangan positif terhadap karir atau pekerjaannya kedepan (Ram \& Prabhakar, 2011). Karyawan yang engaged adalah mereka yang secara sepenuhnya hadir secara psikologis saat bekerja dan mau benar-benar berusaha untuk mencapai kesuksesan (Sundaray, 2011). Selain itu, mereka memiliki kecenderungan untuk percaya bahwa akan mendapatkan hasil yang baik (optimis) dan memiliki kepuasan ketika berpartisipasi dalam mematuhi aturan di dalam organisasi (Bakker, 2009). Work engagement akan diwujudkan dalam sikap positif seperti job satisfaction, organizational commitment serta perilaku rendahnya turnover serta tingginya organizational citizenship behaviour. Banyak faktor yang mempengaruhi tingkat engagement pada karyawan di antaranya adalah resiliensi (personal resource) dan iklim organisasi (job resource).

Berdasarkan hasil kategorisasi data penelitian dapat diketahui bahwa tingkat work engagement karyawan PT. Komatsu Indonesia yang tergolong dalam kategori sedang sebanyak 11\%, kategori tinggi sebanyak $89 \%$ dan tidak ada yang masuk dalam kategori rendah. Hasil tersebut menunjukkan bahwa tingkat work engagement pada karyawan PT. Komatsu Indonesia sebagian besar dalam kategori tinggi. Banyak penelitian yang menunjukkan bahwa karyawan yang engaged memiliki emosi positif dan hal tersebutlah yang menjadi alasan kenapa mereka dapat lebih produktif dibandingkan yang lain. Orang yang bahagia akan lebih sensitif menangkap peluang kerja, dan memiliki kemauan untuk membantu orang lain, optimis dan percaya diri (Bakker, 2009).

Hasil analisis yang telah dilakukan menggunakan metode stepwise menunjukkan bahwa hanya variabel prediktor resiliensi yang memiliki peranan yang signifikan terhadap work engagement. Besar sumbangan efektif dari variabel ini adalah $12,9 \%$ yang berarti $87,1 \%$ lainnya dipengaruhi oleh variabel lain yang tidak diukur dalam penelitian ini. Kategorisasi yang dilakukan menunjukkan hasil bahwa tingkat resiliensi karyawan berkisar pada level sedang sebanyak 35\% dan tinggi 41\%.

Hasil penelitian ini juga didukung oleh penelitian yang dilakukan Villavicencio, Jurado dan Valencia pada tahun 2014 bahwa organisasi yang di dalamnya terdapat orangorang yang memiliki resiliensi tinggi akan dapat bersaing di dalam dunia globalisasi. Hal tersebut terjadi karena mereka yang resilien akan lebih dapat mengatasi, menganalisis bahkan merespon dengan tepat terhadap lingkungan yang penuh dengan tantangan. Selain itu, penelitian dari Wang dan Li tahun 2016 juga mengungkap hal 
yang sama, ketika individu yang memiliki resiliensi tinggi menghadapi kesulitan maka mereka cenderung bisa melakukan koping dan adaptasi dengan baik. Hal itu akan berdampak pada munculnya positif afek yang dapat meningkatkan engagement. Karyawan yang engaged tidak hanya memiliki kecenderungan untuk tidak melakukan absenteism tetapi mereka juga sangat terbuka dengan pengalaman (Bakker, 2009).

Karyawan yang memiliki resiliensi tinggi akan memiliki ketahanan, kemampuan untuk menyelesaikan masalah, memiliki pandangan positif terhadap kehidupan, kemampuan untuk merespon tanda-tanda bahaya, kemampuan untuk beradaptasi dan menghadapi perubahan (Anisman, 2015). Individu dengan resiliensi tinggi akan memiliki tingkat penyesuaian psikologi dan tingkat kepercayaan diri yang tinggi yang pada akhirnya akan berdampak pada performa kerja yang baik (Block \& Kremen dalam Embury, 2015). Keadaan tersebut menjadi bekal penting dalam membentuk karyawan yang tangguh ketika dihadapkan pada perubahan-perubahan yang ada di dalam organisasi. Tidak dapat dipungkiri perubahan akan terus ada dan kemampuan beradaptasi karyawan menjadi sangat penting untuk diperhatikan demi terus tercapainya produktivitas.

Sebagai kesimpulannya, ketika karyawan memiliki tingkat resiliensi tinggi maka dapat bekerja di lingkungan seperti apapun dan memiliki cara-cara tersendiri untuk melakukan tugas-tugas pekerjaan mereka. Akibatnya, mereka memiliki keyakinan untuk mengelola tugas-tugas tersebut dan semakin menghargai diri. Individu tersebut akan termotivasi untuk mengejar tujuan, oleh karena itu cenderung engagged dalam mengerjakan apa yang mereka lakukan (Luthans \& Youssef, 2004). Jika karyawan perusahaan sudah memiliki level work engagement tinggi maka mereka akan lebih produktif dan tentunya tujuan organisasi akan mudah tercapai.

Hasil kategorisasi variabel iklim organisasi menunjukkan bahwa mayoritas karyawan PT. Komatsu Indonesia termasuk dalam katogori sedang yaitu $63 \%$, kategori tinggi 37\% dan tidak ada karyawan yang memiliki kategori yang rendah. Pada penelitian ini iklim organisasi merupakan kategori variabel excluded yang artinya variabel tersebut tersingkirkan karena memiliki hubungan tidak signifikan dengan variabel work engagement. Hasil tersebut diperkuat oleh salah satu penelitian yang dilakukan oleh Haugsnes (2016) tentang Investigating the Effect of Organizational Climate on work engagement. Hasil penelitian ini tidak signifikan dalam mengonfirmasi hubungan antara iklim organisasi dan work engagement. Salah satu kemungkinan yang bisa terjadi adalah iklim organisasi harus dimediasi oleh konstruk lain agar dapat mempengaruhi Work engagement.

Teori Job Demands-Resources (JD-R) menyebutkan bahwa iklim organisasi dapat memiliki hubungan dengan keterlibatan kerja melalui persepsi personal resource atau dalam penelitian ini adalah resiliensi (Bakker \& Xanthoupoulu, 2007). Resiliensi tersebut akan menjadi dorongan internal dari karyawan yang memungkinkan mereka dapat mengubah peluang yang disediakan oleh lingkungan ke dalam tindakan yaitu work engagement. Oleh karena itu, resiliensi dapat dianggap sebagai prediktor dari work engagement yang dapat membantu menjelaskan 
mengapa iklim organisasi berhubungan dengan work engagement (Vittala \& Tanskanen, 2015).

Selain itu, keadaan job demand atau tuntutan kerja yang tinggi juga memiliki peran dalam menjelaskan hubungan antara iklim organisasi dan work engagement. Dalam penelitian ini dapat dilihat dari hasil kategorisasi bahwa 63\% karyawan PT. Komatsu menunjukkan iklim organisasi sedang. Keadaan iklim organisasi yang kurang baik akan menyebabkan individu tidak dapat mengurangi efek negatif dari tuntutan kerja sehingga akan kesulitan dalam mencapai tujuan kerjanya. Sebaliknya, apabila iklim organisasi tinggi maka dapat dijadikan sebagai penyeimbang ketika dihadapkan pada beban kerja yang tinggi dan work engagament akan tetap terjaga (Xanthaopoulou dan Bakker, 2007).

Berikut merupakan hasil wawancara yang dilakukan kepada asisten manajer Human Resource Development:

Perusahaan ini sedang menggencarkan penerapan TQM oleh karena itu sangat menghendaki adanya banyak hal yang harus di improve, karena sebelumnya tidak seperti itu maka karyawan tidak terbiasa akan merasakan semua ini menjadi sesuatu yang berat. (W.R.II.01. 34-38.

Pernah ada yang keluar yang kabarnya gara-gara kurang bisa menyesuaikan akibat pemberlakuan TQM ini. Setelah diwawancarai TQM ini memang bagus tetapi harus pelanpelan sambil berjalan (W.R.II.01. 4749)

Wawancara tersebut dapat sedikit menjelaskan mengenai gambaran tuntutan kerja karyawan PT. Komatsu Indonesia.
Adanya perubahan didalam organisasi sedikit banyak berpengaruh terhadap job demand atau tuntutan kerja pada karyawan sehingga akan berpengaruh juga terhadap bagaimana iklim organisasi dapat berperan dalam memprediksikan work engagement. Tuntutan kerja yang tinggi harus diimbangi oleh keadaan iklim organisasi yang tinggi pula agar work engagement dapat tetap tercipta.

\section{Kesimpulan}

Berdasarkan hasil analisis penelitian ini maka dapat disimpulkan bahwa hipotesis yang diajukan ditolak. Resiliensi dan iklim organisasi tidak dapat memprediksikan work engaggament secara bersama-sama. Variabel resiliensi dapat memprediksikan work engagement secara signifikan sedang-kan variabel iklim organisasi tidak dapat memprediksikan work engagement secara signifikan. Sumbangan efektif dari variabel resiliensi terhadap work engagement adalah $12,9 \%$. Oleh karena itu, dapat disimpulkan bahwa untuk meningkatkan work engagment karyawan pada karyawan PT. Komatsu Indonesia dapat dilakukan dengan meningkatkan tingkat resiliensi.

\section{Saran}

Work engagement yang tinggi pada karyawan PT. Komatsu Indonesia diharapkan dapat terus dipertahankan. Cara yang mungkin dapat dilakukan adalah dengan menjaga tingkat resiliensi. Organisasi dapat memperhatikan berbagai macam faktor yang dapat meningkatkan resiliensi di antaranya menciptakan lingkungan kerja yang positif seperti dibiasakan untuk memberikan apresiasi atau penghargaan, membudayakan untuk berbagi senyum, dan saling memberikan dukungan. 
Peneliti selanjutnya diharapkan dapat melakukan penelitian dengan level subjek yang lebih beragam. Tidak hanya pada staf saja tetapi juga mereka yang memiliki jabatan lebih tinggi sehingga akan mendapatkan hasil yang lebih menyeluruh. Selain itu, apabila peneliti selanjutnya ingin melakukan penelitian dengan komposisi variabel yang sama maka dapat menjadikan variabel resiliensi sebagai variabel mediator.

\section{Kepustakaan}

Anisman, H. (2015). Stress and your health from vulnerability to resilience. UK: John Willey.

Badan Pusat Statistik. (2015). Indeks tendensi bisnis dan indeks tendensi konsumen. Jakarta: BPS.

Bakker, A. B. (2009). Building engagement in the workplace dalam Burke R. J., \&. Cooper. C. L. The peak performing organization. UK: Routledge.

Connor K. M., \& Davidson (2003). Development of a new resilience scale: the connor-davidson resilience scale (Cd-Risc). Depression and Anxiety. 18, 76-82.

Embury, S. P. (2013). Resilience in children, adolescents, and adults: Translating research into practice. New York: Springer.

Kahn, W. A. (1990). Psychological conditions of personal engagement and disangagement at work. Academy of Management Journal, 33(4), 692-724.

Kleinbaum, D. G., \& Kupper, L. L. (1978). Applied regression analysis and other multivariabel methods. California: Wadsworth Publishing Company.

Koch, T. C. (2013). Organisational climate and its effect on job engagement: Exploring the mediating effect of employees' level of job satisfaction. Faculty of Humanities University of Cape Town. South Africa.

Komatsu (2012). Profil perusahaan. Diunduh 2

Desember 2016, dari http://www.komi.co.id/ourcompany/company-profile/companyinformation.

Luthans, F. (2002). Positive organizational behaviour: Developing and managing psychological strengths. Academy of Management Executive, 16(1), 57-75.

Luthans, F., \& Youssef, C. (2004). Human, social and now positive psychological capital management: Investing in people for competitive advantage. Organisational Dynamic, 33(2), 143-160.

Mase, A. J., \& Tyokya, T. L. (2014). Resilience and organizational trust as correlates of work engagement among health workers in Makurdi metropolis. European Journal of Business and Management, 6(39), 86-93.

Mc Eween, K. (2011). Building resilience at work. Bowen Australia: Australian Academic Press.

Ram, P., \& Prabhakar, G. V. (2011). The Role of Employee Engagement in Work Related Outcomes. Interdiciplinary of Research in Business, 1(3), 47-61.

Rushton, H. C., Batcheller, J., Schroader, K. \& Donohue, P. (2015). Burnout and resilience among nurses practicing in high- intencity setting. American Assosiation of Critical-Care, 24(5), 412420.

Schaufeli, W. B., \& Bakker, A. B. (2003). UWES - Utrecht Work Engagement Scale: Test manual. Utrecht. The Netherlands: Department of Psychology, Utrecht University. 
Scneider, B., Ehrahart, G. M., \& Macey, W. H. (2013). Organization climate and culture. Annual Review Psychology, 64, 61-88.

Suarez, E. P., Muniz, J., Alvarez, A.C., Pedrero, E. F \& Cueto, E. G. (2013). Assessing organizational climate: Psychometric properties of the CLIOR Scale. Psychothema, 25(1), 137-144.

Sundaray, B., K. (2011). Employee Engagement: A Driver of Organizational Effectiveness. European Journal of Business and Management, 3(8). 53-60.

Villavicencio, E., Jurado, S., \& Valencia, A. (2014). Work Engagement And Occupational Burnout: Its Relation To
Organizational Socialization And Psychological Resilience. Journal of Behavior, Health \& Social Issues, 6(2), 4555.

Vittala, R., \& Tanskanen, R. (2015). The Connection between oganizational Climate and Well-being at Work. International Journal of Organizational Analysis, 23(4), 606-620.

Waluyo, M. (2013). Psikologi industri. Jakarta: Akademia Permata.

Xanthaopoulou, D., \& Bakker, E., Demerouti, E., \& Schaufeli, W. B (2007). The role of personal resources in the job demendsresources model. International Journal of Stress Management, 14(2), 121-141. 